\title{
Impact of Kaizen-like Practices in the Brazilian Manufacturing Sector
}

\author{
Filipe Lage de Sousa, Mauricio Canêdo-Pinheiro, \\ Bernardo Pereira Cabral, and Glaucia Estefânia de \\ Sousa Ferreira
}

F. Lage de Sousa $(\bowtie)$

Department of Economics, Fluminense Federal University (UFF), Niterói, Brazil

Research Department, Brazilian Development Bank (BNDES),

Rio de Janeiro, Brazil

e-mail: fl_sousa@id.uff.br

M. Canêdo-Pinheiro

Brazilian School of Economics and Finance (FGV EPGE), Rio de Janeiro, Brazil

Faculty of Economic Sciences, Center for Social Sciences, University of Rio de Janeiro State-UERJ, Rio de Janeiro, Brazil

B. Pereira Cabral

Faculty of Economics, Federal University of Bahia, Salvador, Brazil

G. E. de Sousa Ferreira

Economic Commission for Latin America and the Caribbean, United Nations/

CEPAL, Rio de Janeiro, Brazil

(C) The Author(s) 2020

A. Hosono et al. (eds.), Workers, Managers, Productivity, https://doi.org/10.1007/978-981-15-0364-1_10 


\section{INTRODUCTION}

Productivity has always been a relevant topic among economists and policymakers. Interest is understandable since productivity is the main factor for long-term economic growth. Krugman (1994) coined an expression that shows its importance: "Productivity isn't everything, but in the long run it is almost everything. A country's ability to improve its standard of living over time depends almost entirely on its ability to raise its output per worker." Based on this acknowledgment, economists try to understand the determinants of productivity and their effectiveness to promote sustainable development. For instance, management and innovation are considered key internal drivers for productivity growth by the literature (Syverson 2011).

The Brazilian economy has benefited substantially after the entrance of China in the international market due to the terms of trade change. ${ }^{1}$ The abundance of resources provided opportunities to expand government support in different areas, especially on innovation. Indeed, the volume of government support to foster innovation in Brazil has increased substantially in the last years. These government policies have also reached a different spectrum of firms, as there were new financial tools to support innovation. One example is the creation of new credit lines in 2008 designed to support exclusively innovation by the Brazilian Development Bank (BNDES is its acronym in Portuguese). The surge of these policies was influenced by impact evaluation assessment of BNDES schemes. For instance, (Ottaviano and Lage de Sousa 2008) found limited impact of existent financial support on productivity from this development bank, which was explained by the lower emphasis on innovation in supported projects. ${ }^{2}$ Additionally, there was also a shift in government policies toward more support for innovation in the private sector rather than government support for innovation activities made in universities and research centers (Cânedo-Pinheiro 2013). As an illustration, 6.4\% of Brazilian manufacturing firms have received government support to innovate in 2005, while the same share reached 14.5\% in 2014 (Cânedo-Pinheiro and Figueiredo 2017).

On one hand, the existent literature shows that, in general terms, these government policies to support innovation in the private sector worked reasonably well. There is evidence that, everything else constant, the public support increased the innovative efforts in the private sector, not merely crowded out other sources of private funding to innovation (CânedoPinheiro and Figueiredo 2017). On the other hand, other evidence shows 
that these policies were not so successful. For example, outcomes regarding new products and processes do not correspond to the quantity of financial resources allocated in this period. After an initial increment between 2005 and 2008, the percentage of innovative firms in the manufacturing sector reduced from $38.4 \%$ in 2008 to $36.3 \%$ in $2014 .^{3}$ A similar trend was observed for expenditures on innovation (such as its share in terms of sales), according to the Brazilian innovation surveys.

Although there is a substantial amount of work done in terms of how innovation affects productivity, we are not aware of any research investigating how management practices can improve firms' productivity in the Brazilian economy, even more on specific management practice that requires low level of investment, as Kaizen. The relevance of management on productivity differences is considerable; Bloom et al. (2016) estimated that differences in management practices account for about $30 \%$ of crosscountry total factor productivity differences. In the international arena, management practices of the private sector in developing countries, including Brazil, are lagging behind developed countries (N. Bloom et al. 2012). Moreover, firms with low-quality management practices are concentrated at the bottom of the productivity distribution in developing countries, which implies that improving the quality of management practices constitutes an opportunity to close productivity gaps not only between firms within a given industry in a country but also between developed and developing countries. ${ }^{4}$

This chapter tries to evaluate how Kaizen management practice has been able to improve firms' performance looking at quantitative and qualitative approaches. To the best of our knowledge, this is the first attempt to combine these two approaches to evaluate how Kaizen is able to boost firms' performance. This is particularly relevant in the context of an economy struggling to recover from the worst period of recession in its economic history. Not only fiscal constraints from the Brazilian government are binding any supplemental support, but also the private sector does not have sufficient resources to invest substantially in the next years. Therefore, improvements in firm's performance with low levels of investment should be a norm in the next years.

Our main findings suggest a productivity premium for implementing Kaizen. On average, Kaizen adopters show labor productivity $14.5 \%$ higher than similar non-adopters and total factor productivity $8 \%$ superior comparing with similar firms. However, investigating when this impact materializes on those starting to implement it during the investigated 
period, we were not able to detect it. However, we found robust evidence that Kaizen induces innovation, which is a catalyzer for productivity improvements in the long term. Nevertheless, it is important to emphasize that our qualitative approach corroborates our quantitative findings that productivity is achieved only in the long term and innovation is achieved immediately. Therefore, our interpretation consists of Kaizen as an effective tool to raise innovation in the short term and productivity in the long term.

To make this assessment, this chapter is organized as follows. Section 2 describes the dataset used in our quantitative approach, followed by how Kaizen might be inferred using innovation surveys in Sect. 3. Section 4 presents our empirical strategy from the quantitative approach and interpretation of the outcomes is shown in Sect. 5. Section 6 presents our qualitative methodology, including data collection and selection criteria. The outcomes of our qualitative approach are discussed in Sect. 7. Last section (Sect. 8) provides our concluding remarks.

\section{Brazilian Firm-Level Datasets}

For our quantitative investigation, we require firm-level dataset in order to assess whether Kaizen is able to impact firm's performance. The Brazilian Statistical Institute (IBGE) provides microdata at firm level from two relevant surveys: the Brazilian Innovation Survey (Pesquisa de Inovaçao Tecnologica-PINTEC) and the Annual Manufacturing Survey (Pesquisa Industrial Anual-PIA).

PINTEC is a sample survey, inspired by the Oslo Manual from Organisation for Economic Co-operation and Development (OECD), which means that it is comparable to other similar surveys worldwide. Six waves of this survey are available (1998-2000, 2001-2003, 2003-2005, 2006-2008, 2009-2011 and 2012-2014), which enables us to follow firms over a certain period if the questions related to management practices are consistent over time. PINTEC's sample is stratified with respect to firm size (number of employees), sector, state and innovation potential. Firms with less than 10 employees are not surveyed and larger firms (with 500 or more employees) are allocated in a specific stratum and selected with probability equal to one (certain stratum). Remaining firms are allocated to sampled strata, which were defined by crossing information on state and sectors. These strata (called natural strata) are then subdivided into two strata (called final strata): one with potential innovators and other 
with the remaining firms. ${ }^{5}$ The sample is disproportionately allocated in these two final strata, so that approximately $80 \%$ of the firms selected for a sample, in each natural stratum, are companies very likely to be innovative. ${ }^{6}$ Although extremely restrictive, more than 4400 firms from the manufacturing sector participated in the 2014 innovation survey. ${ }^{7}$

The PIA database contains information that allow us to build a measure of firm productivity and other key explanatory variables such as number of employees, investments in physical capital and others. This annual survey initiated in the 1986, but a consistent approach started only after 1996 and remains the same until 2014. PIA comprehends all manufacturing firms over 30 employees, which means a census for firms over this threshold. Firms from 5 to 30 employees are randomly surveyed in PIA. On average, around 30,000 firms are surveyed annually in the census part (over 30 employees).

Since the same institution (IBGE) elaborates these two surveys, they share similar methodological aspects, such as the identical sector classification, which follows the International Standard Industry Classification (ISIC). Since both datasets use the same firm identification, we are able to merge them.

\section{Kaizen Identified in an Innovation Survey}

From an empirical perspective, our study faces the challenge of identifying the Kaizen adoption because we do not have the information whether a firm has implemented this management approach. However, we are able to develop a taxonomy to identify firms adopting management practice based on Kaizen's principle. This can be considered a contribution on using innovation surveys to define Kaizen adopters when this information is not available.

Although PINTEC provides information on whether firms have implemented management practices in all six waves of this survey, questions change overtime, hampering us to use all years available. However, the last three innovation surveys provide identical questions on management. This consistency in the questionnaires enables us to create an approach to distinguish whether firms are implementing Kaizen style of management practice. Nevertheless, firms need to be present in the three waves for us to define which firms are continuously implementing a management practice, as this is a requirement for being considered a Kaizen. Therefore, we restricted our sample to a balanced panel of firms from these three waves. 
In this survey, they consider as an organizational innovation any implementation of new management practice or significant changes in the division of labor within the firm as well as in the external relations with clients or suppliers. These changes must aim to improve their knowledge, efficiency in their operations or in the quality of its goods and services. They should also be a consequence of the strategic decisions of firm's directors and a new organizational method for the firm. Although this definition seems extremely broad, they do not consider merging and acquisition as an organizational innovation, even if this is the first time.

Given this background to what is considered an organizational innovation, firms reply to the survey to whether they have implemented any new management practice to improve their routines and labor practice in the last three years. Under this concept, examples of new management practices are re-engineering, knowledge management, total quality control, training activities, enterprise resource planning and others. Therefore, replying affirmative to this question is just an indication to whether the firm could be implementing Kaizen, since we do not know if it involves all the employees or that it is a continuous process. Complementary information is needed to refine the identification of Kaizen approach.

Following this initial question on management practice, the questionnaire further asks if new methods of labor organization aiming to delegate responsibilities for achieving better decision-making, such as new managing working teams, restructuring departments or others in a similar fashion. Since Kaizen requires labor participation to improve their operations, we consider this as a second characteristic of this management practice.

Last, another feature of Kaizen is the recurrent improvements in firm's operations. In other words, it requires continuous changes in their business practice. Therefore, we define as a Kaizen management approach if a firm has answered affirmatively to both questions described previously in recurrent years.

Considering the definition provided in the previous paragraphs, the distribution of firms implementing or not Kaizen are described in Fig. 10.1. First, our balanced panel comprehends 2185 firms available in both datasets described previously. In terms of Kaizen, around $57 \%$ of the firms have implemented this management practice over the period investigated. ${ }^{8}$ However, implementation of Kaizen occurs in distinct periods and firms are evenly distributed overtime whether they have implemented in three, two or only in the last survey year. ${ }^{9}$ 


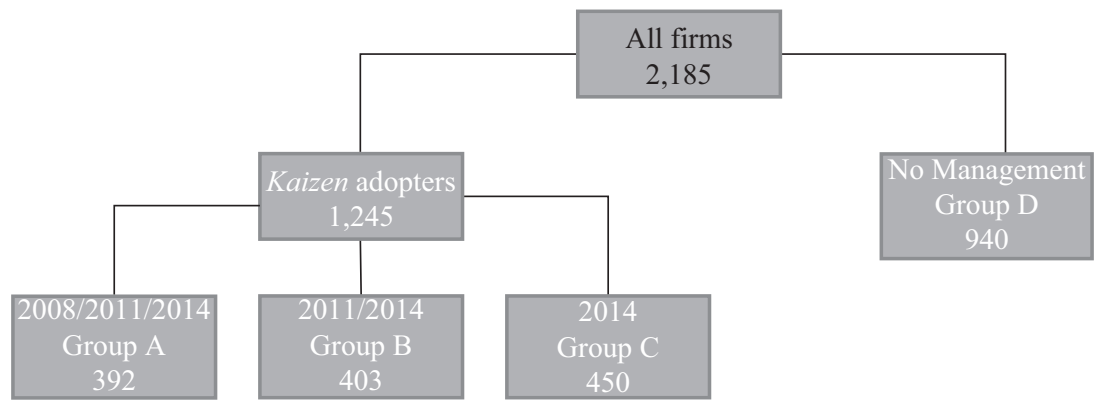

Fig. 10.1 Distribution of firms implementing Kaizen

\section{Empirical Strategy from the Quantitative ApProACH}

Given the distribution of firms in the categories described in the previous section, two different strategies are able to pursue. Initially, our best candidates as firms implementing Kaizen are those that continuously replied yes to both questions overtime. This comprehends those firms implementing Kaizen over the three survey years investigated (Group A). Our initial approach is to compare them with those that have not implemented any management practice (Group D).

Although Group A is the most proper group to be considered as a Kaizen management style, since they have implemented constantly from 2006 to 2014, we do not know when they have adopted this management method. As the gains of Kaizen might be when they have started this management approach, it is relevant to investigate when the firm begins the implementation of Kaizen. Therefore, we assume that firms carrying out Kaizen approach based on the last two PINTEC (Groups B and C, respectively) are also candidates to investigate the effects on firm's performance after the implementation of this management practice.

Empirical strategy to investigate the effects of Kaizen for Groups A, B and $\mathrm{C}$ cannot be identical, as they have their particularities on when they have implemented this management practice. In Group A, we are not aware of when the firm started carrying out Kaizen. Therefore, our strategy should be what the bonus of implementing this Japanese management practice is. Comparing the performance between groups is an initial approach, but firms from either group might be biased. Firms might have 
different characteristics because Kaizen was not randomly assigned between firms. A feasible approach to reduce this selection bias is implementing one-to-one propensity score matching (PSM) with replacement and average treatment effect (ATE) sequentially. ${ }^{10}$

As for the other comparison groups (B and C vs. D), we implement a combination of PSM and difference-in-differences (DID). Since we know when firms began implementing the management practice, we use preand post-intervention years to establish the effect. Since the groups of firms implementing Kaizen or not are not randomly assigned, we perform a one-to-one PSM with replacement in 2008 (pre-Kaizen), select only those matched firms in the control group and perform a DID for the whole period.

\section{ECONOMETRIC ResULTS}

As described in the empirical strategy, our results are presented using two approaches. First, our treated group consists of firms that have implemented Kaizen continuously during all period investigated. Based on the previous description of the empirical strategy, our first approach is to perform PSM with Groups A versus D. In order to implement the PSM, it is essential to estimate what the relevant indicators that influence the adoption of Kaizen are. Therefore, a Probit is estimated using a dummy for the adoption of Kaizen as the dependent variable and a number of characteristics as independent variables. Table 10.1 provides us the results on which indicators are relevant determinants for the implementation of Kaizen.

At first, most of the characteristics used are relevant determinants for the adoption of Kaizen and they present economic interpretation. Productivity, innovation (product and process), physical investment per worker, share of R\&D workers and multinational status present a positive corresponding estimated parameter, which means that they tend to increase the probability to adopt Kaizen. Furthermore, firms with higher margin tend to have lower incentives to implement Kaizen, which is also consistent with the idea firms facing higher competition tend to implement more Kaizen. This evidence is further corroborated by the measure on how markets are concentrated. In sectors with higher concentration (less competition), firms have fewer incentives to improve their performance through the implementation of Kaizen. ${ }^{11}$ Therefore, competition seems to be a key driver for Kaizen adoption. 
Table 10.1 Kaizen's determinants (Probit)

Probit estimation-Kaizen dummy as the dependent variable

\begin{tabular}{llll}
\hline Variables & Parameter & Standard deviation & p-value \\
\hline Labor productivity & $0.055 *$ & $(0.033)$ & 0.097 \\
Costs/revenue & 0.086 & $(0.056)$ & 0.125 \\
Margin & $-0.138 *$ & $(0.083)$ & 0.096 \\
Exports/revenue & -0.001 & $(0.001)$ & 0.623 \\
Product innovation & $0.493 * * *$ & $(0.060)$ & 0.000 \\
Process innovation & $0.642 * * *$ & $(0.059)$ & 0.000 \\
Number of workers & 0.107 & $(0.189)$ & 0.571 \\
No. of workers squared & 0.018 & $(0.015)$ & 0.218 \\
Production workers/total & $-0.419 * * *$ & $(0.133)$ & 0.002 \\
R\&D workers/total & $3.789 * * *$ & $(0.992)$ & 0.000 \\
Physical invest per worker & $0.084 * * *$ & $(0.019)$ & 0.000 \\
Competition (HHI) & $-0.639 * *$ & $(0.322)$ & 0.047 \\
Multinational & $0.151 * *$ & $(0.071)$ & 0.032 \\
Firm's growth & -0.019 & $(0.085)$ & 0.826 \\
Observations & 3456 & Pseudo $R$-squared & 0.2545 \\
$R$-squared & Yes & Constant & Yes \\
\hline
\end{tabular}

Notes: Robust standard errors in parentheses. $* * * p<0.01, * * p<0.05, * p<0.1$

Source: Authors' Elaboration

Table 10.2 Results of ATE (Group A vs.

Group D)

\begin{tabular}{lll}
\hline Variables & ATE & P-value \\
\hline Labor productivity & $0.145 * * *$ & 0.004 \\
TFP Levinsohn and Petrin & $0.084 *$ & 0.065 \\
TFP Olley and Pakes & $0.085 *$ & 0.100 \\
\hline
\end{tabular}

$* * * p<0.01, * * p<0.05, * p<0.1$

Source: Authors' Elaboration

After matching Kaizen's adopters and non-adopters based on these characteristics, the following procedure is to see if there is a premium for implementing Kaizen in different measures of productivity by ATE, see Table 10.2. ${ }^{12}$

Among all productivity measures considered, our outcomes suggest a premium of $14.5 \%$ in labor productivity and of $8 \%$ in total factor productivity. ${ }^{13}$ Thus, this evidence informs us that Kaizen's firms tend to have a higher performance compared to other not implementing any management practice even after controlling for the important determinants of its 
adoption. Considering that Kaizen adopters are implementing this management practice for at least nine years, our initial interpretation is that productivity improvements are observed in the long term. However, we do not have information of some firms' characteristics that might be affecting our results as well as we do not know what happens after the introduction of Kaizen management practice. ${ }^{14}$ These issues should be considered in order to uncover when these impacts materialize.

Our analysis shifts to those firms that we assumed that they have adopted Kaizen during the investigated period. First, we need to evaluate whether our matching pre-Kaizen shows reasonable adherence between adopters and non-adopters. A way to show that is by checking whether the distribution of $p$-score from Kaizen and non-Kaizen firms becomes similar after the matching. Figure 10.2 shows the $p$-score $K$-density before and after the matching. As observed, the distributions are similar even before the PSM, but after pairing non-adopters with Kaizen firms differences diminish.

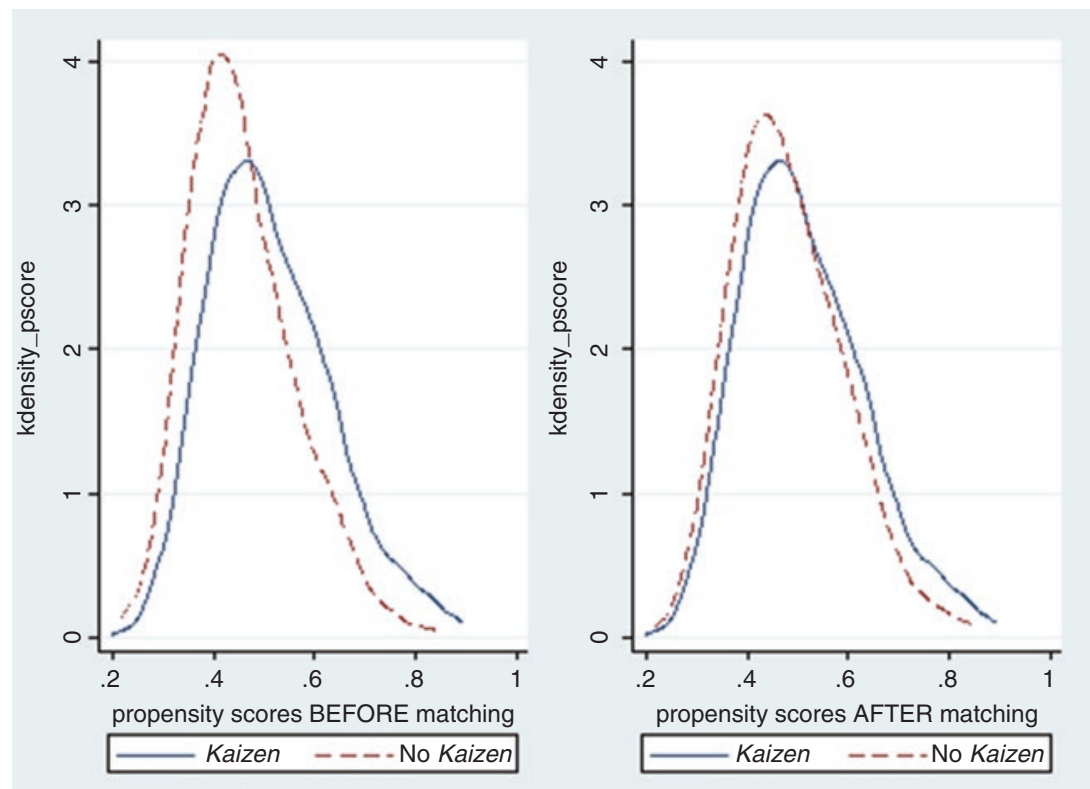

Fig. 10.2 K-density of Kaizen adopters and non-adopters groups in 2008: Groups B, C versus Group D. (Source: Authors' Elaboration) 
Table 10.3 shows our DID results contrasting those treated firms against a group of matched firms that have not implemented any kind of management practice. ${ }^{15}$ We have investigated not only productivity measures but also other indicators, yet we will present only those showing robust evidence in the DID. In other words, all other performance indicators do not show any kind of impact from implementing Kaizen, such as firms' growth, margin and others. ${ }^{16}$ Therefore, our focus on the results of the DID approach is productivity (labor and Total Factor Productivity [TFP]); firm's size; product and process innovation; and share of R\&D workers. Columns for each variable are first without any control followed by another considering the full set of controls and last considering only the sectors that we have interviewed in our qualitative approach. ${ }^{17}$

Before looking at the impact of Kaizen, we have selected a control to show in this table: multinational. ${ }^{18}$ As observed, multinationals are positively related to most of our investigated variables, which is the expected result. Considering the Kaizen's impact, initially we observe that Kaizen is not able to improve firm's productivity after its implementation, neither at its labor productivity nor at its TFP. Therefore, our interpretation is: it requires a longer period to observe an impact of Kaizen on firm's productivity. Considering that we observed a productivity premium in the ATE while comparing Groups A and D, our interpretation is that Kaizen promotes productivity gains but when it materializes it is not feasible to detect in a short period, at least not during our investigated period (six years from the two last waves from PINTEC). Therefore, our conclusion is that Kaizen might induce higher productivity in the long term (maybe over a decade), while in the short term firms still need to adapt to this new management approach and benefits are not observed in the short run. ${ }^{19}$ This is further corroborated by the only positive result obtained of productivity when restricting the samples to solely those sectors investigated in our qualitative approach. In this subgroup of firms, the positive impact is observed in labor productivity, which is considered a short-term productivity compared to TFP.

In other variables, we are able to see positive effects from Kaizen adoption. For instance, there are robust results on Kaizen increasing firm's size, measured by the number of employees. As the share of production workers is not impacted from the DID approach, yet share of R\&D workers is, we conclude that this expansion of employees is biased toward high-skilled workers. Thus, Kaizen adopters tend to become larger than non-adopters by increasing the number of skilled workers. Aside number of employees, 


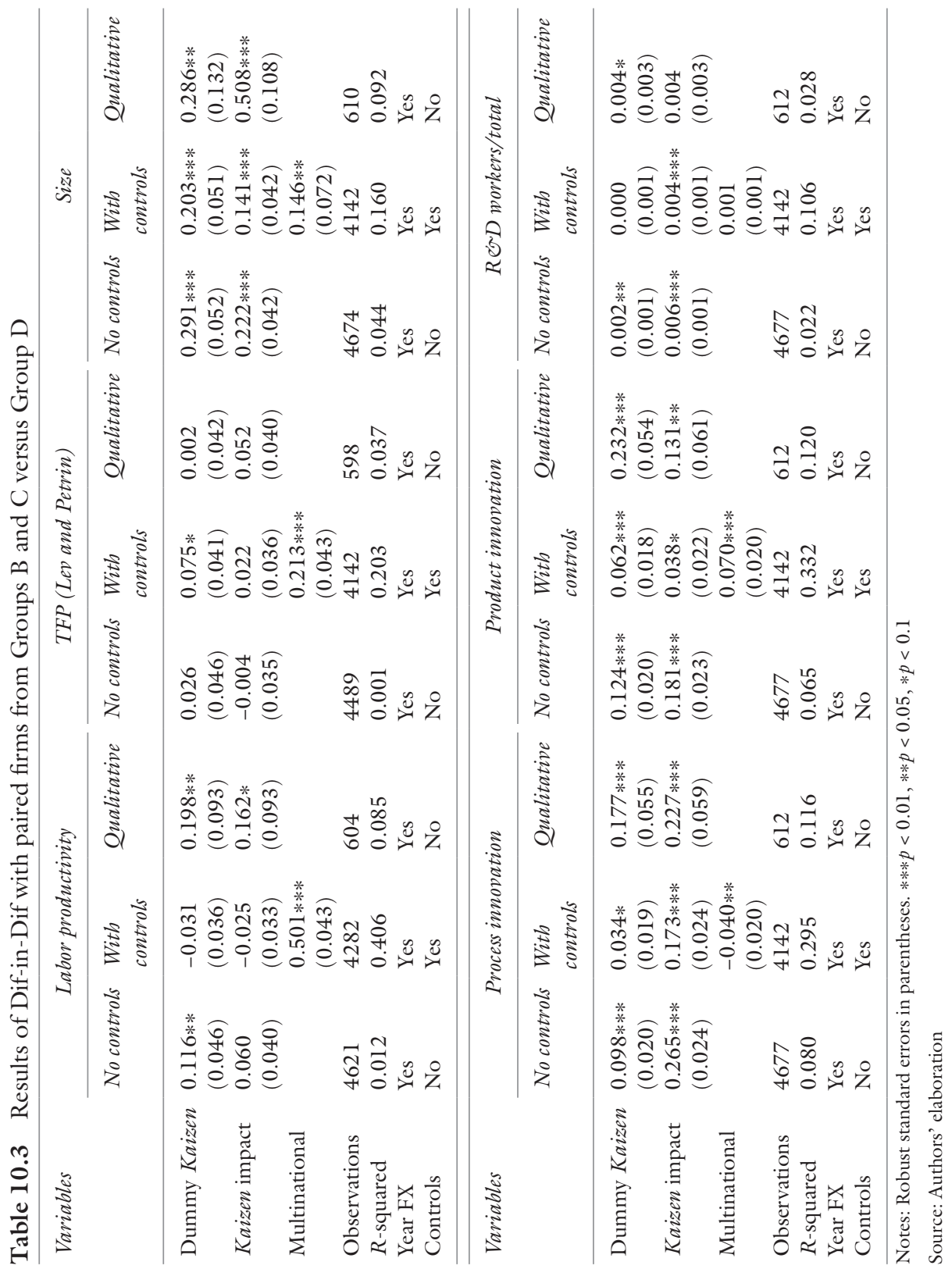


it is also feasible to see a robust impact on product and process innovations. As Kaizen is a management practice with the involvement of the full workforce, in which each employee is entitled to suggest changes, an increase of innovation as a whole is a sign that Kaizen promotes exchange of ideas to improve firm's performance. As they are innovation outputs, both are able to induce higher productivity as described by the literature of innovation, see the model proposed by Crepon et al. (1998). So, our conclusion is that Kaizen can impact productivity determinants in the short term, yet productivity per se only in the long run. ${ }^{20}$

\section{Qualitative Approach: Methodology and Data}

\subsection{Research Design and Methodology}

Our qualitative approach aims to complement the results from the quantitative analysis regarding the effects of Kaizen on the performance of Brazilian firms. The specific objective is to clarify our outcomes including counterintuitive ones. We generalize our findings from case study research following the literature (Eisenhardt 1989).

We use a CAQDAS (Computer Assisted Qualitative Data Analysis Software) called NVivo to organize, manage and analyze our qualitative data. NVivo is a proprietary software commonly used for qualitative analysis like ours (Bazeley and Jackson 2013) and is referred to as an excellent tool to explore multiple meanings in the data (Richards 2002) to become aware of gaps in the collected data (Wickham and Woods 2005), to revisit data with new conceptual lens and to reflect on social construction of research evidences (Kaczynski and Kelly 2004).

NVivo offers a range of visualization possibilities that are used to better understand and analyze our interview samples. First, we use a case map to link words that were used by our interviewees - this gives us best sense of how the nodes (words) tell the history from the perspective of each participant. Then, we use a chart to compare our data and to give us an alternative view of our results. We also create relationships between the main concepts of our research and use it to better analyze the data.

Our main goal in the software is to make a qualitative matrix analysis, where information from interviewed firms is compared and analyzed. This is an efficient way to contrast data from all in-depth interviews and it helps to make sure no information is lost on the analysis process. From there, we 
get a set of valid statements that encompass the findings of the quantitative analysis and new specific findings from the qualitative analysis.

\subsection{Selection Criteria and Data Collection}

Our first step is to establish that focus is on the object (Kaizen) rather than the subject (firm). Therefore, chosen firms for our qualitative analysis need to meet only one criterion: use Kaizen in its productive activities in Brazil. There are a few Kaizen adopters in Brazil, but we chose three with different capital ownership and industrial activities. They are from high and medium-high technology sectors based on the OECD technological intensity and are controlled by Asian shareholders. Two of the firms adopted Kaizen since its creation, but the other one adopted Kaizen only recently - in 2015. Moreover, two firms are suppliers of the third one.

To meet our goals, the selected companies were contacted by e-mail. We took advantage of Japan International Cooperation Agency's (JICA) network of contacts and recognition in Brazil to establish contact with companies; hence, all of them have Asian ownership. We interviewed different employees from those companies and all interviews took place between March and June of 2018. The interviewees are involved with Kaizen taskforces in the companies, but have different working backgrounds, age and position. People responsible for the company appointed the interviewees to us. All the interviews were recorded and transcribed and average time per interview was 30 minutes.

We used a semi-structured questionnaire with open-ended questions. An interview guide was used in the meetings to assist the researchers throughout the interviews. We used a standard questionnaire and also created specific questions for each of our interviewees taking in account their position and working background in the firm. We emphasize that the aim of our qualitative approach was to complement the results found in the quantitative analysis regarding Kaizen activities in Brazil.

The precise object of the interview was not to explicitly answer the questions, but to get deeper impressions of Kaizen activities in the firm. The interviewees were encouraged to speak freely in their answers, since our questionnaire was constructed with open-ended questions. We captured information that reflected the variability needed to understand the phenomenon studied in the research (Patton 2002) and the collected cases provided relevant examples of the phenomena under scrutiny (Siggelkow 2007) with minimum of analytical generalization (Yin 2009). 


\section{Qualitative Outcomes and Discussion}

We organize the research findings from our qualitative matrix analysis and data generated by NVivo into two different set of results: (1) those that could give us a deeper understanding of the quantitative results and (2) those that aimed to enhance our understanding of Kaizen practices within the firm.

\subsection{Kaizen-Adopter Firms and Their Employees}

First, it is important to share some of the main answers of our interviewees regarding what it means to work in a Kaizen-adopter firm. All of them stated that their work experience changed after getting more in touch with the Kaizen philosophy, despite their previous knowledge of this management practice. Most of the statements regarded the search for the root problem in every aspect of industrial production and for a deeper understanding of the firm's processes. Kaizen implies a search for permanent solutions, not only quick and short-term remedies for industrials bottlenecks.

An interesting aspect of the influence of Kaizen in the interviewee's daily life is related to their positions in the firm. Kaizen is applicable to all company's areas, but the interviewees said that they felt how it really worked only after they got in touch with the production assembly lines. Since continuous improvements are easier to see in an assembly line rather than an office space-especially because of metrics-it makes sense that Kaizen is seen as more important in the production area. That was the case for all the interviewees, since production assembly lines looked more suited to Kaizen practices than other firm's departments. This is consistent with our findings that the share of production workers of Kaizen adopters is lower; thus this management practice is labor saving in the production line in the long term.

\subsection{Competitive Pressure and the Search for Improvements Without Increasing Expenses}

An interesting discussion topic emerged when interviewees were asked why firms adopted Kaizen. On one hand, in the firms that carried out Kaizen since its creation, they were emphatic saying that Kaizen is intrinsically associated to their organizational culture. On the other hand, the 
other firm stated that Kaizen was adopted in order to achieve higher competitiveness and recover market share lost to other firms that previously adopted Kaizen. Therefore, this acknowledgment corroborates our findings in the quantitative analysis, which shows the relevance of competition as a key determinant of Kaizen adoption.

All our interviewees also highlight another important aspect of Kaizen: the search for improvements without increasing expenses. According to many of the interviewees, the main idea of Kaizen is to improve their performance by spending nearly nothing. Our empirical findings on the lack of impact of Kaizen on investment of physical capital per worker validate these qualitative assessments. One strategy for the firms is to reduce the amount of reprocessing, for example, the number of times the same process is done on the assembly line. This emphasizes the firm's concern on process innovation, which is highly associated with Kaizen adoption in our quantitative analysis. Product innovation is indeed less highlighted though changes in the process areas may improve the quality of the final product.

Another interesting result from our interviews is how employee participation may explain some of the continuous improvement in the firms. Employees in all firms are demanded to propose suggestions often and are rewarded financially or by recognition within the firm. Financial compensation is modest and is regarded as symbolic by our interviewees, but it is an effective way to engage employees in making suggestions. Those suggestions often result in small yet important changes in the assembly line, which correlate with process innovation improvements.

\subsection{Kaizen and Brazilian Business Environment}

It is also important to situate efficacy of Kaizen as a management tool in Brazil's business environment considering some of the recent economic fluctuations in the domestic market. Despite using Kaizen for decades, employees affirm that the downturn in sales after 2008 was extremely important to improve some of the Kaizen techniques in the firm. For one of them, it was the perfect moment to deepen Kaizen practices within the firm. All firms needing to reduce costs look for Kaizen as a cheap and effective way to turn the tide. For the largest firm, it was also a timely moment to share these practices with its suppliers more vehementlybefore 2008, these suppliers were surfing in the economic boom and did not see the need to implement Kaizen tools. However, after 2008, some 
suppliers asked for help to implement Kaizen and ultimately that meant a better relationship between the firm and its suppliers.

Our interviewees shared their experience working with Kaizen for years in their production site, but also reported experiences in other production sites-including in other countries. Cultural and business environment often changes when one is working in a different place, but our interviewees said there is always room for improvement regardless the location. Kaizen adapts to different scenarios and results can be seen in short, medium and long term if it is used correctly.

\subsection{Kaizen's Impacts in the Companies}

An interesting result came after we asked the employees about their recent results regarding Kaizen. One of the interviewees told us that they canceled the contract of more than 100 professionals when assessing the implementation of a new plant, most of them from the production line. This result corroborates our empirical findings that Kaizen adopters tend to have lower percentage of production workers. However, as explained by the interviewee, this work created a demand for workers with higher levels of education to verify the efficiency of the plant. Given this outcome, two conclusions emerge. Although it is difficult to generalize, first, when implementing Kaizen, firms tend to hire more employees than others since production expands more than those not implementing Kaizen, because these firms present a steady growth, which confirms our empirical findings on total number of employees. Second, it provides some evidence that by implementing Kaizen, firms might increase demand for skilled workers rather than non-skilled workers (from production line). However, further research using more detailed information on workers' skills (such as education and experience) available in other datasets is required to investigate the impact on workers' heterogeneity. ${ }^{21}$

Our interviewees stated that the benefits of continuous improvements may not reflect in productivity in the short term because most of the efficiency gains are on improving the time at work from employees in the production line, which not necessarily increases the speed of producing a good. For example, one suggestion from employees to use their working time in a most efficient way could be to clean the work station after each unit of product instead of cleaning it only at the end of the work day. This change generates more organized workplaces and generates a sense of greater importance for the work. There are also many Kaizen practices 
that help diminish environment impacts but do not translate into higher profits or productivity in the short run, even being considered equally important.

At the end, we saw that most of Kaizen efforts affect firms in medium and long term, especially because it takes time for the employees to really believe in these tools. Our quantitative outcomes are in line with these views because a productivity premium exists (ATE), but it is not detectable after Kaizen implementation (DID).

\section{Concluding Remarks}

In this chapter, we investigate the effects of Kaizen on firm's performance in Brazil not only using a quantitative approach but also using a qualitative one. Overall, our argument is that Kaizen is an appropriate approach to improve firm's performance, especially in a context of financial constraints because it requires low levels of investments. Moreover, a more competitive environment tends to induce firms to implement Kaizen.

Our quantitative empirical outcomes suggest a productive premium for Kaizen adopters. When comparing the performance of adopters versus non-adopters, our outcomes identify a premium of $14.5 \%$ on labor productivity and $8 \%$ on TFP in Brazilian firms when estimating the average treatment effect. This evidence shows that Kaizen is able to improve firms' productivity not only in naïve measures (labor productivity), but also sophisticated one (TFP using (Olley and Pakes 1996; Levinsohn and Petrin 2003)). However, our evidence is not able to detect whether this improvement in productivity is observed in a short-term period (six years) when estimating the impact by difference-in-differences approach. Our conclusion is that Kaizen has a long-term effect that requires a reasonable period to obtain the gains of implementing this management practice.

Nevertheless, our results suggest that Kaizen is an important tool to enhance innovation. In our difference-in-differences approach, product and process innovation is increased after the implementation of Kaizen. These are innovation outputs that eventually impact productivity. Therefore, we believe that the channel for Kaizen impacting productivity is through the causality well established in the literature of innovation, which is innovation output leading to productivity improvement. Our interpretation in this regard is based on our results that we detect an impact of Kaizen on innovation on firms implementing this management 
practice, while the productivity premium is noticed in Kaizen adopters for around a decade at minimum. Another side effect of Kaizen is that adopters tend to increase their size after implementing it, since we observed that number of workers increase in firms implementing Kaizen, especially those in R\&D activities.

Our qualitative approach evidenced that the impact of Kaizen on firms' productivity is a long-term process, since improvements might not be accounted for in the short term. However, there is a general feeling of improvement in other aspects right after implementing Kaizen practices that translate to better results after some time. Therefore, we believe that time horizon investigated in this chapter to verify when these effects on productivity materialize requires a long period.

\section{Notes}

1. For instance, the demand for commodities rose after the entrance of China in the World Trade Organization (WTO), as a consequence boom in commodities' price surged. Brazil, like many other developing countries, exports many commodities, which were benefited by the change of the terms of change.

2. Other papers include (Ribeiro and De Negri 2009; Lage de Sousa 2013; Negri et al. 2011; Lage de Sousa and Ottaviano 2018; Pires and Russell 2017).

3. In 2005 , percentage of innovative firms in the manufacturing sector was $33.4 \%$.

4. For a discussion on how management practice impacts innovation and productivity, see (Page 2020) and (Hosono 2020).

5. In summary, potential innovators are defined by IBGE as firms that, in the survey period, were included in the registers of beneficiaries of innovation public policies or in the Brazilian patent registers. The ones that were innovators in the previous surveys are also defined as potential innovators.

6. In natural strata where the total number of firms in the population is less than or equal to five, all firms are included in the sample with probability of selection equal to one.

7. PINTEC covers all manufacturing sector and only some from Services: telecommunications, information technology, Engineering/Architecture and Research \& Development. As the number of firms in these Services is restrictive, we focus our analysis on the manufacturing sector.

8. We have excluded all firms which have answered erratically these two described questions, which means not consistent across them and/or not overtime. 
9. Descriptive statistics from a wide range of indicators are available upon request.

10. As differences between adopters and non-adopters are minimal, we have chosen to implement one-to-one PSM with replacement as even the most sophisticated PSM might present outcomes similar to the chosen one.

11. We use Herfindahl-Hirschman Index (HHI) as a measure of concentration. HHI is calculated by squaring the market share of each firm competing in a market and then summing the resulting numbers.

12. Two measures of Total Factor Productivity (TFP) are considered (Olley and Pakes 1996; Levinsohn and Petrin 2003). Further details are available upon request.

13. For the ATE, we considered all variables used in the Probit model apart from productivity measures.

14. For instance, information on capital ownership, such as whether it is a family-owned firm, is not available and there is robust evidence in the literature that family-owned firms are less productive.

15. Results using only B or C groups provide similar results and are available upon request.

16. Outcomes using these other variables are available upon request.

17. As the number of observations drops dramatically, we decided to present the results without using any control.

18. Outcomes with full set of controls are available upon request.

19. As DID eliminates any time-invariant unobservable variables, such as ownership, another explanation might be that now after eliminating these unobservable factors, firms do not differ in terms of productivity.

20. Results are qualitative similar using all firms from Group D and are available upon request.

21. Relação Anual de Informaçao Social (RAIS) from the Ministry of Labor provide detailed information of each formal Brazilian firm.

\section{REFERENCES}

Bazeley, Patricia, and Kristi Jackson. 2013. Qualitative Data Analysis with NVivo. 2nd ed. Sage Publications. https://doi.org/10.1080/14780887.2014.992750.

Bloom, N., C. Genakos, R. Sadun, and J. Van Reenen. 2012. Management Practices Across Firms and Countries. Academy of Management Perspectives 26 (1): 12-33. https://doi.org/10.5465/amp.2011.0077.

Bloom, Nicholas, Raffaella Sadun, John Van Reenen, Orazio Attanasio, Marianne Bertrand, Robert Gibbons, John Halti-wanger, et al. 2016. Management as a Technology?. NBER Working Paper 22327 (16-133). https://doi. org/10.1017/CBO9781107415324.004. 
Cânedo-Pinheiro, M. 2013. Inovação No Brasil: Panorama Geral, Diagnóstico E Sugestões de Política. In Armadilha Da Renda Média: Visões Do Brasil E Da China, ed. F.A.A. Veloso, L.V. Pereira, and Z. Bingwen, 81-106. Rio de Janeiro: FGV.

Cânedo-Pinheiro, M., and Paulo Figueiredo. 2017. Inovação Tecnológica E Produtividade Industrial No Brasil. In Anatomia Da Produtividade No Brasil, ed. Armando Pinheiro Castelar, Regis Bonelli, and Fernando Veloso, 211-240. FGV.

Crepon, Bruno, Emmanuel Duguet, and Jacques Mairessec. 1998. Research, Innovation and Productivity: An Econometric Analysis at the Firm Level. Economics of Innovation and New Technology 7 (2): 115-158. Routledge. https://doi.org/10.1080/10438599800000031.

Eisenhardt, K.M. 1989. Building Theories from Case Study Research. Academy of Management Review 14 (4): 532-550. https://doi.org/10.5465/ AMR.1989.4308385.

Hosono, Akio. 2020. Kaizen Towards Learning, Transformation, and HighQuality Growth: Insights from Outstanding Experiences. In Workers, Managers, Productivity: Kaizen in Developing Countries, ed. Akio Hosono, John Page, and Go Shimada, 45-67. Singapore: Palgrave Macmillan.

Kaczynski, Dan, and Melissa Kelly. 2004. Curriculum Development for Teaching Qualitative Data Analysis Online. QualIT 2004: International Conference on Qualitative Research in IT and IT in Qualitative Research, no. November: 9.

Krugman, Paul. 1994. The Age of Diminished Expectations: U.S. Economic Policy in the 1990s. The MIT Press 31 (1-2): 197-201. https://doi. org/10.1016/0022-1996(91)90067-G.

Lage de Sousa, Filipe. 2013. How Can Development Banks Boost Firms' Productivity? In Development Evaluation in Times of Turbulence, 115-142. The World Bank. https://doi.org/10.1596/9780821398791_CH09.

Lage de Sousa, Filipe, and Gianmarco I.P. Ottaviano. 2018. Relaxing Credit Constraints in Emerging Economies: The Impact of Public Loans on the Productivity of Brazilian Manufacturers. International Economics 154: 23-47. https://doi.org/10.1016/j.inteco.2017.11.002.

Levinsohn, James, and Amil Petrin. 2003. Estimating Production Functions Using Inputs to Control for Unobservables Estimating Production Functions Using Inputs to Control for Unobservables. Review of Economic Studies 70 (70): 317-341. https://doi.org/10.1111/1467-937X.00246.

Negri, João Alberto, Alessandro Maffioli, César Rodríguez, and Gonzalo Vázquez. 2011. The Impact of Public Credit Programs on Brazilian Firms. No. IDB-WP-293. Washington, DC. https://publications.iadb.org/ handle/11319/3826\#sthash.huG2Kjk2.dpufDe. 
Olley, G. Steven, and Ariel Pakes. 1996. The Dynamics of Productivity in the Telecommunications Equipment Industry. Econometrica 64 (6): 1263. https:// doi.org/10.2307/2171831.

Ottaviano, Gianmarco I.P., and Filipe Lage de Sousa. 2008. O Efeito Do BNDES Na Produtividade Das Empresas. Politicas de Incentivo À Inovação Tecnológica No Brasil.

Page, John. 2020. Industrial Policy, Firm Capabilities and Kaizen. In Workers, Managers, Productivity: Kaizen in Developing Countries, ed. Akio Hosono, John Page, and Go Shimada, 29-44. Singapore: Palgrave Macmillan.

Patton, Michael Quinn. 2002. Qualitative Research and Evaluation Methods. Qualitative Inquiry, 3rd ed. ISBN: 9781412972123.

Pires, Jose Claudio, and Nathaniel Russell. 2017. Assessing Firm-Support Programs in Brazil. Washington, DC. https://doi.org/10.18235/0000939.

Ribeiro, Eduardo Pontual, and João Alberto De Negri. 2009. Public Credit Use and Manufacturing Productivity in Brazil. Mimeo.

Richards, Lyn. 2002. Rigorous, Rapid, Reliable and Qualitative? Computing in Qualitative Method. American Journal of Health Behavior 26 (6): 425-430.

Siggelkow, Nicolaj. 2007. Persuasion with Case Studies. Academy of Management Journal 50 (1): 20-24. https://doi.org/10.5465/AMJ.2007.24160882.

Syverson, Chad. 2011. What Determines Productivity? Journal of Economic Literature 49 (2): 326-365. https://doi.org/10.1257/jel.49.2.326.

Wickham, Mark, and Megan Woods. 2005. Reflecting on the Strategic Use of CAQDAS to Manage and Report on the Qualitative Research Process. The Qualitative Report 10 (4): 687-702.

Yin, Robert K. 2009. Case Study Research: Design and Methods. By Robert K. Yin. Applied Social Research Methods Series, vol. 5. https://doi.org/10.1097/ FCH.0b013e31822dda9e. 
Open Access This chapter is licensed under the terms of the Creative Commons Attribution 4.0 International License (http://creativecommons.org/licenses/ by $/ 4.0 /)$, which permits use, sharing, adaptation, distribution and reproduction in any medium or format, as long as you give appropriate credit to the original author(s) and the source, provide a link to the Creative Commons licence and indicate if changes were made.

The images or other third party material in this chapter are included in the chapter's Creative Commons licence, unless indicated otherwise in a credit line to the material. If material is not included in the chapter's Creative Commons licence and your intended use is not permitted by statutory regulation or exceeds the permitted use, you will need to obtain permission directly from the copyright holder.

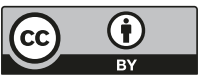

